\title{
Quality of anticoagulant therapy and the incidence of in-stent thrombosis after venous stenting
}

\author{
Pascale Notten $\mathrm{MD}^{1,2}$ (D) | Jorinde H. H. van Laanen $\mathrm{MD}^{1} \quad$ Pieter Eijgenraam $\mathrm{PhD}^{3}$ | \\ Mark A. F. de Wolf MD, PhD ${ }^{1,2,4,5}$ | Ralph L. M. Kurstjens MD, PhD ${ }^{1,2,6}$ | \\ Hugo ten Cate MD, $\mathrm{PhD}^{2,3,7}$ | Arina J. ten Cate-Hoek MD, $\mathrm{PhD}^{2,3,7}$
}

${ }^{1}$ Department of Vascular Surgery, Maastricht University Medical Centre, Maastricht, the Netherlands

${ }^{2}$ CARIM, School for Cardiovascular Diseases, Cardiovascular Research Institute Maastricht, Maastricht University Medical Centre, Maastricht, the Netherlands

${ }^{3}$ Laboratory for Clinical Thrombosis and Hemostasis, Maastricht University, Maastricht, the Netherlands

${ }^{4}$ Department of Radiology, Maasstad Hospital, Rotterdam, the Netherlands

${ }^{5}$ Department of Radiology, Erasmus Medical Centre, Rotterdam, the Netherlands

${ }^{6}$ Department of Obstetrics and Gynaecology, Leiden University Medical Centre, Leiden, the Netherlands

${ }^{7}$ Heart + Vascular Centre and Thrombosis Expertise Centre, Maastricht University Medical Centre, Maastricht, the Netherlands

\section{Correspondence}

Arina J ten Cate-Hoek, Thrombosis

Expertise Centre, Heart + Vascular Centre,

Maastricht University Medical Centre, P.

Debyelaan 25, 6229 HX Maastricht, the

Netherlands.

Email: arina.cate@mumc.nl

Handling Editor: Susan Kahn

\begin{abstract}
Background: In patients with a venous outflow obstruction following iliofemoral deep vein thrombosis stenting of the venous tract to prevent or alleviate postthrombotic syndrome is applied with increasing frequency. The impact of the quality of anticoagulant therapy with vitamin $\mathrm{K}$ antagonists (VKAs) on the development of in-stent thrombosis is currently unknown.
\end{abstract}

Objectives: To determine the association between the quality of postinterventional VKA treatment and the occurrence of in-stent thrombosis.

Methods: Seventy-nine patients with iliofemoral and/or caval venous stent placement for obstruction of the venous outflow were included in this study. All patients received postinterventional VKA. The quality of VKA anticoagulant therapy was expressed as the time within therapeutic range (TTR) calculated using the linear interpolation method and as the proportion of International Normalized Ratio (INR) values < 2.0. In-stent thrombosis was assessed by the use of duplex ultrasound. Survival analysis (Kaplan-Meier curves, Cox regression) was used to analyze the data. Results: In-stent thrombosis developed in 16 patients (20.3\%). The total population had a mean TTR of $64.0 \%( \pm 19.0)$ and a mean proportion of INR values $<2.0$ of $11.6 \%( \pm 12.0)$. Overall, a TTR $<49.9 \%$ was associated with an increased risk of instent thrombosis. The multivariable adjusted analysis showed a hazard ratio (HR) of 0.96 (95\% confidence interval $[\mathrm{Cl}], 0.92-0.99 ; P=.02)$ per $1 \%$ increase in TTR. The proportion of INR values $<2.0$ had no significant association with the occurrence of in-stent thrombosis: $\mathrm{HR} 0.98(95 \% \mathrm{Cl}, 0.91-1.06 ; P=.66)$.

Conclusions: We conclude that the quality of anticoagulant treatment reflected in the TTR following a venous stenting procedure is an important independent determinant for the risk of in-stent thrombosis. The role of anticoagulant treatment for the prevention of in-stent thrombosis following stenting procedures therefore merits further research. 


\section{KEYWORDS}

anticoagulants, deep vein thrombosis, International Normalized Ratio, postthrombotic

syndrome, stents

\section{Essentials}

- Uniform evidence-based guidelines on anticoagulant management after venous stenting are lacking.

- This study assessed quality of vitamin K antagonist (VKA) therapy and its role in in-stent thrombosis.

- We found a decreased risk of in-stent thrombosis with increasing time within therapeutic range.

- Quality of VKA therapy after stenting is an important determinant for risk of in-stent thrombosis.

\section{1 | INTRODUCTION}

Percutaneous transluminal angioplasty (PTA) and venous stenting of the caval and iliofemoral veins have become more common and are considered to be effective and safe treatment modalities for eliminating (central) venous outflow obstructions and the restoration of venous flow. Literature suggests good mid- to long-term patency rates as well as objective and subjective clinical improvement. ${ }^{1-5}$ However, in-stent thrombosis is the most important complication that can diminish effectiveness or reverse treatment outcomes.

Venous stenting is thought to restore the venous outflow, to reduce postthrombotic morbidity in case of residual venous flow obstructions following acute iliofemoral deep vein thrombosis (DVT), and/or to relieve symptoms if postthrombotic syndrome (PTS) or chronic deep venous pathology have already developed. Despite adequate conservative treatment involving early anticoagulation, early compression therapy, and early mobilization, PTS will develop in $25 \%-50 \%$ of patients with an acute iliofemoral DVT. ${ }^{6-8}$ Venous stenting can be performed in the acute phase as an adjunct to catheter-directed thrombolysis (CDT), when there is underlying venous pathology (ie, iliac vein compression syndromes), or in the chronic phase to alleviate complaints when residual venous obstruction due to postthrombotic changes are present. ${ }^{9-13}$ Venous stenting is most frequently considered for chronic deep venous obstructions, either due to compression syndromes, acquired causes (eg, postthrombotic synechiae), or congenital causes (eg, anatomic anomalies).

Thus far, there is no consensus regarding the postprocedural anticoagulant management. ${ }^{14,15}$ Current international guidelines do not provide specific recommendations on anticoagulation therapy after venous stenting mainly due to lack of evidence. ${ }^{16} \mathrm{~A}$ large variety in anticoagulant management following venous stent placement either for chronic venous obstruction or directly after CDT in the acute thrombotic phase has been reported. ${ }^{14}$ Despite the rapidly increased use of direct oral anticoagulants (DOACs), treatment with vitamin $\mathrm{K}$ antagonists (VKAs) still appears to be preferred by clinical experts. ${ }^{14,15}$ The duration of anticoagulant therapy varies from 3 to 12 months, usually with a target International Normalized Ratio (INR) range of 2.0-3.0. ${ }^{15}$ While time within therapeutic range (TTR) of VKA therapy in acute DVT is known to have substantial impact on recurrent DVT, ${ }^{17,18}$ the role of TTR during VKA therapy for the prevention of in-stent thrombosis after venous stenting remains unknown. In addition, INR values < 2.0 are an established risk factor for both recurrent venous thromboembolism ${ }^{17}$ and PTS. ${ }^{19,20}$ Taking this into consideration, we hypothesized that the quality of anticoagulation most likely also influences the effectiveness of venous stenting in relation to stent patency.

Therefore, we evaluated the association of the quality of postinterventional VKA anticoagulation with the occurrence of in-stent thrombosis following caval and/or iliofemoral venous stenting, both in the acute postthrombotic phase and in the setting of chronic deep venous obstruction.

\section{2 | METHODS}

\section{1 | Study design and patient selection}

Patients were recruited from a cohort study that was followed at the Maastricht University Medical Centre, the Netherlands, between March 2009 and January 2013. Data on the interventions were collected prospectively and were entered in a cohort database. In all patients, the indication for venous stent placement, being either the prevention or treatment of PTS with the presence of an acute or chronic obstruction of the caval and/ or iliofemoral vein segments, was objectified. Patients were eligible only if VKA was used for at least 3 months following the performed intervention and follow-up data of at least 1 year were available. In total, 108 patients from this cohort, who were treated at the Department of Vascular Surgery with venous stent placement for either acute cavo-iliofemoral DVT or chronic deep venous obstructions, met inclusion criteria and were invited to participate in the current study. Ultimately, 79 patients $(73.1 \%)$ consented and were included in this study. All patients were required to provide informed consent to retrieve data regarding their INR measurements from their anticoagulation clinic records. Institutional review board approval was obtained (METC 14-4-081). 


\section{2 | Treatment}

\subsection{1 | Preinterventional workup}

A standardized preinterventional workup was performed in all patients in the cohort and consisted of clinical evaluation, extensive duplex ultrasound assessment, and magnetic resonance venography Clinical assessment was used to determine the presence and severity of signs, symptoms, and complaints. Duplex ultrasound assessed the inferior caval vein as well as the separate vein segments of the affected leg (ie, common iliac vein, external iliac vein, common femoral vein, femoral vein, deep femoral vein, and popliteal vein) for underlying pathology, signs of flow impairment, recanalization, lumina narrowing, vein wall thickening, and external compression. Magnetic resonance venography was used to visualize the extent and severity of intraluminal postthrombotic changes, external compression, and collateralization, as well as the exact location of the trabeculae within the venous lumen. ${ }^{21}$

The localization of the initial obstruction indicative for venous stenting was described using the lower-extremity thrombosis (LET) score, which categorized patients into 1 of 4 categories ( $I=$ calf veins II = femoropopliteal, III = femoroiliac, IV = inferior caval vein) based on the results from the preinterventional workup imaging studies. ${ }^{22}$

\subsection{2 | Venous stenting}

Indications for venous stent placement were classified as either acute cavo-iliofemoral thrombosis, or chronic deep venous obstruction due to the presence of postthrombotic sequelae (ie, PTS with postthrombotic synechiae), or (nonthrombotic) iliac vein compression syndromes. Patients were treated with PTA and stenting. Stenting in the acute thrombotic phase was usually performed following treatment with ultrasound-accelerated CDT.

All procedures were performed in a dedicated angio suite under sedation. In patients using VKA at the time of intervention, the procedure was performed under full anticoagulation (ie, VKAs were continued in the days preceding the intervention in the case of an INR < 4.0). If patients did not have anticoagulant therapy, 5.000 International Units (IU) of unfractionated heparin was administered at the start of the procedure. Another $5.000 \mathrm{IU}$ was given at the discretion of the treating physician in case of a prolonged duration of the intervention. In case ultrasound-accelerated CDT was performed prior to the stenting procedure, patients were treated with therapeutic doses of low-molecular-weight heparin (LMWH) during thrombolysis and VKA treatment was temporarily interrupted.

Venous access was obtained via the ipsilateral popliteal vein under ultrasound guidance, preferably at least $15 \mathrm{~cm}$ distal to the deep femoral confluence. Venous thrombolysis was performed using Urokinase (Medacinase, Lamepro) and the Ekos Endowave system (EKOS Corporation). Recanalization, PTA, and venous stenting were performed according to international and local guidelines. ${ }^{5,23}$ Following recanalization, PTA and subsequent stenting of the affected vein segments was performed. The proximal and distal landing zones of the stents were placed in seemingly healthy vein segments, meaning the absence of trabeculations. A hybrid procedure including endophlebectomy was performed in case the intraluminal synechiae obstructed the femoral junction. If a low inflow of the recanalized vein segment was anticipated or observed during preoperative venography, an arteriovenous fistula using a loop-shaped external supported polytetrafluoroethylene graft was created.

Self-expandable stents with diameter sizes ranging from 12 to $16 \mathrm{~mm}$ in the iliofemoral tract to $24 \mathrm{~mm}$ in the caval tract were used in all cases: Sinus-XL, Sinus-XL Flex, Sinus-Venous (Optimed), Zilver Vena (Cook). To reconstruct the confluence of the vena cava in the limited number of patients with bilaterally affected iliac tracts, balloon expandable stents such as the AndraStent (Andramed) were used. $^{23}$

\subsection{3 | Postinterventional anticoagulation therapy}

In patients using VKA prior to the intervention, anticoagulant therapy was continued for at least another 6 months. All other patients were started on LMWH directly after the procedure and were started on a VKA according to international guidelines concomitantly at the first postinterventional day, after which VKA was continued for at least 6 months. ${ }^{24}$ VKA therapy was targeted at an INR range of either 2.03.5 or 2.5-4.0. The preferred target INR and treatment duration was at the discretion of the treating physician.

\section{3 | Clinical follow-up}

Following the intervention, standard clinical follow-up was performed at the outpatient clinic after 2 and 6 weeks, as well as after 3 , 6 , and 12 months and annually thereafter. Recurrence of symptoms could necessitate earlier consultations and assessments.

At every follow-up visit, a standardized clinical evaluation was performed by the treating physician recording signs, symptoms, and complaints, as well as the use of anticoagulants, experienced bleedings, in-stent thrombosis, or recurrent venous thromboembolism. Duplex ultrasound was performed to assess the patency of the (stented) venous tract. Treatment decisions regarding anticoagulation, compression therapy, and reinterventions were based on these assessments.

The severity of complaints was measured using the ClinicalEtiological-Anatomical-Pathophysiological (CEAP) classification ${ }^{25}$ and Venous Clinical Severity Score (VCSS) ${ }^{26}$. The VCSS differentiates venous disease severity into absent (0-3), mild to moderate (47), or severe ( $\geq 8){ }^{27}$

Patient records were retrieved from the patient's individual anticoagulation clinic to ascertain start and stop dates of VKA treatment, other indications for VKA therapy, target INR, type of VKA used (acenocoumarol or phenprocoumon), measured INR values, and 
whether adjunctive treatment with LMWH was instructed in case of INR values $<2.5$ beyond the initial treatment period.

\subsection{Definition of outcomes}

Primary outcome was the incidence of in-stent thrombosis, which was defined as an objectified (recurrent) thrombotic event leading to a full obstruction in the stented trajectory.

Quality of anticoagulant treatment was described by the TTR as well as proportion of INR values $<2.0$ for the overall treatment time. The linear interpolation method as proposed by Rosendaal et $\mathrm{al}^{28}$ was used to calculate the TTR. This method assumes a linear relationship in time between 2 INR measurements.

Bleeding complications were registered and categorized following the definition as stated by the ISTH. ${ }^{29}$ Major bleedings included (a) fatal bleedings, (b) symptomatic bleedings in critical areas or organs (intracranial, intraspinal, intraocular, retroperitoneal, intra-articular, pericardial, or intramuscular), or (c) causing a fall in hemoglobin of $\geq 2 \mathrm{~g} / \mathrm{dL}(\approx 1.24 \mathrm{mmol} / \mathrm{L})$ or the need for a transfusion of $\geq 2$ units of packed red blood cells or whole blood.

\section{5 | Statistical analysis}

Descriptive statistics were used to compare baseline characteristics. Continuous variables are reported as means \pm standard deviations (SD) or medians with their interquartile ranges (IQRs) as appropriate. Categorical data are presented by their absolute numbers and corresponding percentages. Baseline data are presented based on prescribed target INR, either "low" (target INR, 2.0-3.5) or "high" (target INR, 2.5-4.0). The outcome data were presented according to the different treatment indications: acute cavo-iliofemoral DVT and chronic deep venous obstruction due to postthrombotic sequelae, or nonthrombotic pathology (eg, compression syndromes). To compare groups, parametric and nonparametric tests were performed as appropriate.

Receiver operating characteristic (ROC) curves were used to determine the cutoff points for the outcome in stent thrombosis in relation to TTR and the proportion of INR values $<2.0$, respectively. Based on expected differences seen in the literature, ${ }^{18,30}$ cutoff points were determined for the entire population as well as restricted to the population with acute DVT and the population with chronic deep venous obstruction due to postthrombotic sequelae, respectively. The cumulative risk of in-stent thrombosis based on the determined cutoff values for the entire population is presented using Kaplan-Meier curves. Patients were censored when follow-up ended due to terminated VKA therapy or at the last performed patency measurement. To compare groups, log-rank tests were performed. Person time was calculated from the date of intervention up to the date that in-stent thrombosis occurred, VKA therapy was terminated or the last reported patency measurement was performed. TTRs were compared between patients with and without in-stent thrombosis for the entire population, as well as restricted to DVT patients with acute DVT and chronic deep venous obstruction separately.

Cox regression was used to express the association between the independent variables TTR and percentage of INR measurements $<2.0$ separately. Analyses were performed restricted to patients treated for chronic deep venous obstruction as a result of postthrombotic sequelae and adjusted for possible confounders in relation to the development of in-stent thrombosis.

The risk for in-stent thrombosis is presented using hazard ratios with their accompanying 95\% confidence intervals (95\% Cls). Selection of variables to be included in the multivariable-adjusted models was based either on the association between exposure and the development of in-stent thrombosis as described in the literature or on the observed association in our data $(P<0.20)$. Ultimately, the multivariate model included the variables age at inclusion, sex, VKA type used (acenocoumarol or phenprocoumon), and adjunctive LMWH use if INR value was $<2.5$ beyond the initial treatment period. The proportional hazards assumption was tested for all variables.

A significance level of 0.05 (two-sided) or less was considered significant. As $<5 \%$ of missing data were encountered, no imputation was performed. All analyses were performed using SPSS, version 25 (IBM Corporation).

\section{3 | RESULTS}

Seventy-nine of the 108 eligible patients (73.1\%) provided informed consent to retrieve additional data from their individual anticoagulation clinic and could therefore be included in this study. Forty (50.6\%) patients had a "low" target INR (INR range, 2.0-3.5) and 39 (49.4\%) patients had a "high" target INR (INR range, 2.5-4.0). Baseline characteristics are presented in Table 1. Overall, patients were predominantly female $(n=52,65.8 \%)$ and had a mean age of $41.3 \pm 15.5$ years. Most thrombi were located in the left lower extremity ( $n=47,59.5 \%$ ) and were classified as LET-III ( $n=53,67.1 \%){ }^{22}$ Disease severity differed between groups with patients on a "high" target INR more frequently known with a previous, healed venous ulcer (CEAP-C $5^{25} 7$ [17.9\%] vs 1 [2.5\%] respectively; $P=.02$ ) and reporting a higher severity of venous complaints according to the $\operatorname{VCSS}^{26}(8.92 \pm 3.52$ vs $6.27 \pm 2.66$ respectively, $P=.03$ ).

Neither primary nor secondary outcomes differed between patient groups based on treatment indication (Table 2). In-stent thrombosis developed in 16 patients (20.3\%) after a median of 67.0 (6.0-264.5) days within a median follow-up of 1200 (1037-1363) days. Four patients (25.0\%) were stented during the acute postthrombotic phase and 12 (75.0\%) patients for chronic postthrombotic deep venous obstruction $(P=.27)$. No in-stent thromboses occurred in patients stented for a nonthrombotic indication.

All primary interventions included PTA as well as stent placement. An adjunctive endophlebectomy, creation of an arteriovenous fistula, or a combination of both was performed in 3 (3.8\%), 2 $(2.5 \%)$, and $14(17.7 \%)$ patients, respectively. Venous stenting was 
TAB LE 1 Baseline Characteristics

\begin{tabular}{|c|c|c|c|}
\hline & $\begin{array}{l}\text { Low INR } \\
\text { range, } n=40\end{array}$ & $\begin{array}{l}\text { High INR } \\
\text { range, } n=39\end{array}$ & Total, $\mathrm{n}=79$ \\
\hline Age, y, mean & $42.9( \pm 16.1)$ & $39.7( \pm 12.8)$ & $41.2( \pm 14.5)$ \\
\hline Sex, male & $11(27.5)$ & $16(41.0)$ & $27(34.2)$ \\
\hline \multicolumn{4}{|c|}{ Indication for venous stenting } \\
\hline Acute DVT & $6(15.0)$ & $4(10.3)$ & $10(12.7)$ \\
\hline $\begin{array}{l}\text { Chronic } \\
\text { postthrombotic } \\
\text { sequelae }\end{array}$ & $30(75.0)$ & $34(87.2)$ & $64(81.0)$ \\
\hline $\begin{array}{l}\text { Nonthrombotic causes } \\
\text { (eg, compression } \\
\text { syndromes) }\end{array}$ & $4(10.0)$ & $1(2.6)$ & $5(6.3)$ \\
\hline \multicolumn{4}{|l|}{ Affected side } \\
\hline Left & $25(62.5)$ & $22(56.4)$ & $47(59.5)$ \\
\hline Right & $5(12.5)$ & $8(20.5)$ & $13(16.5)$ \\
\hline Bilateral & $7(17.5)$ & 7 (17.9) & $14(17.7)$ \\
\hline Unknown & $3(7.5)$ & $2(5.1)$ & $5(6.3)$ \\
\hline \multicolumn{4}{|l|}{ LET classification $^{a}$} \\
\hline IV & $6(15.0)$ & $7(17.9)$ & $13(16.5)$ \\
\hline III & $26(65.0)$ & $25(64.1)$ & $51(64.6)$ \\
\hline Unknown & $4(10.0)$ & $6(15.4)$ & $10(12.7)$ \\
\hline Not applicable & $4(10.0)$ & $1(2.6)$ & $5(6.3)$ \\
\hline VCSS, mean ${ }^{\text {bc }}$ & $6.27( \pm 2.66)$ & $8.92( \pm 3.52)$ & $7.50( \pm 3.32)$ \\
\hline \multicolumn{4}{|c|}{ CEAP classification. Clinical score ${ }^{d}$} \\
\hline $\begin{array}{l}\text { C6: Active venous } \\
\text { ulcer }\end{array}$ & $2(5.0)$ & $3(7.7)$ & $5(6.3)$ \\
\hline $\begin{array}{l}\text { C5: Healed venous } \\
\text { ulcer }^{c}\end{array}$ & $1(2.5)$ & $7(17.9)$ & $8(10.1)$ \\
\hline $\begin{array}{l}\text { C4: } \\
\text { Lipodermatosclerosis } \\
\text { or atrophie blanche }\end{array}$ & $8(20.0)$ & $10(25.6)$ & $18(22.8)$ \\
\hline $\mathrm{CO}-\mathrm{C}^{\mathrm{e}}$ & $24(60.0)$ & $17(43.6)$ & $41(51.9)$ \\
\hline Unknown & $5(12.5)$ & $2(5.1)$ & $7(8.9)$ \\
\hline Previous $\mathrm{DVT}^{\mathrm{f}}$ & 35 (87.5) & $35(89.7)$ & $70(88.6)$ \\
\hline Ipsilateral & $31(88.6)$ & $34(97.1)$ & 65 (92.9) \\
\hline Contralateral & $1(2.9)$ & $1(2.9)$ & $2(2.9)$ \\
\hline Bilateral & $3(8.6)$ & $0(0.0)$ & $3(4.2)$ \\
\hline \multicolumn{4}{|l|}{ Previous DVT, cause } \\
\hline Unprovoked & $10(28.6)$ & $7(20.0)$ & $17(24.3)$ \\
\hline Provoked & $25(71.4)$ & $28(80.0)$ & $53(75.7)$ \\
\hline \multicolumn{4}{|c|}{ Previous DVT, contributing risk factors ${ }^{\mathrm{g}}$} \\
\hline Immobility & $1(4.0)$ & $3(10.7)$ & $4(7.5)$ \\
\hline Surgical procedure & $7(28.0)$ & $7(25.0)$ & $14(26.4)$ \\
\hline Trauma & $5(20.0)$ & $5(17.9)$ & $10(18.9)$ \\
\hline Use of contraceptives & $8(32.0)$ & $5(17.9)$ & $13(24.5)$ \\
\hline Pregnancy & $6(24.0)$ & 8 (28.6) & $14(26.4)$ \\
\hline
\end{tabular}

(Continues)
TABLE 1 Continued

\begin{tabular}{cccc} 
& $\begin{array}{c}\text { Low INR } \\
\text { range, } \mathrm{n}=40\end{array}$ & $\begin{array}{l}\text { High INR } \\
\text { range, } \mathrm{n}=39\end{array}$ & Total, $\mathrm{n}=79$ \\
\hline $\begin{array}{c}\text { Thrombophilia, tested } \\
\text { Antiphospholipid } \\
\text { syndrome }\end{array}$ & $12(30.0)$ & $14(35.9)$ & $26(32.9)$ \\
Factor V Leiden $^{\mathrm{h}}$ & $1(8.3)$ & $0(0.0)$ & $1(3.8)$ \\
G20210A mutation $^{\mathrm{h}}$ & $0(0.0)$ & $1(7.1)$ & $12(46.2)$ \\
No thrombophilia & $8(66.7)$ & $5(35.7)$ & $13(50.0)$
\end{tabular}

Note: Results of the baseline characteristics are in $\mathrm{n}(\%)$ or mean ( \pm $\mathrm{SD})$. Apart from the variables marked with ' $c$ ', none of the variables mentioned in this table showed statistical significant differences between groups.

CEAP, Clinical, Etiological, Anatomical, and Pathophysiological classification; DVT, deep vein thrombosis; LET, lower-extremity thrombosis; VCSS, Venous Clinical Severity Score.

${ }^{a}$ The LET classification categorizes DVT of the lower extremity based on its most cranial localization in reference to the vein segments affected. ${ }^{22}$ LET I = calf vein thrombosis, LET II = femoropopliteal thrombosis, LET III = femoroiliac thrombosis, LET IV = inferior caval vein thrombosis.

${ }^{\mathrm{b}}$ The VCSS represents the severity of venous pathology based on 10 indicative features being pain, varicose veins, venous edema, skin pigmentation, inflammation, induration, active ulcers (including number, size, and duration) and the application of compression therapy. It is a dynamic score with a higher score (range, 0-30) meaning more severe complaints. ${ }^{26}$ The score differentiates between no (0-3), mild to moderate (4-7), or severe venous disease $(\geq 8){ }^{27}$

${ }^{\mathrm{c}} P=.03$.

${ }^{\mathrm{d}}$ The CEAP-classification is a standardized score for chronic venous disorders describing its clinical (C), etiological (E), anatomical (A), and pathophysiological (P) characteristics. ${ }^{25}$

${ }^{\mathrm{e}}$ Highest clinical CEAP scores included either C3 (edema), C2 (varicose veins), C1 (telangiectasias or reticular veins), or C0 (no signs of disease). ${ }^{f}$ Previous DVT as reported by the patient during study assessment. ${ }^{\mathrm{g}} \mathrm{A}$ patient can have multiple risk factors.

${ }^{\mathrm{h}}$ One patient was both heterozygote for factor $\mathrm{V}$ Leiden as well as heterozygote for G20210A mutation.

most frequently performed in the left venous tract ( $n=61,77.2 \%$ ), either isolated ( $n=36,45.6 \%$ ) or combined with stent placement in the right and/or caval venous tract $(n=14,17.7 \%$ and $n=11,13.9 \%$, respectively).

Acenocoumarol was the most commonly prescribed anticoagulant during the postinterventional VKA therapy: $57.0 \%$ versus $41.8 \%$ using phenprocoumon. The median duration of VKA treatment was 351 (136-769) days. During treatment, there were no differences in mean INR, TTR, or proportion of INR $<2.0$ between patients stented for acute DVT or chronic deep venous obstruction with chronic postthrombotic sequelae, or nonthrombotic causes: mean INRs were 3.08 ( \pm 0.63$), 3.15( \pm 0.46)$, and $3.12( \pm 0.38), P=.30$; mean TTR, 66.8\% ( \pm 13.6$), 63.2 \%( \pm 19.5)$, and $67.7 \%( \pm 24.9), P=.80$; and the proportion of INRs $<2.0$ were $17.3 \%( \pm 17.9), 10.7 \%( \pm 10.5)$, and $12.2 \%( \pm 15.4)$, $P=.35$, respectively. Supplementary use of LMWH if INR dropped below 2.5 beyond the initial treatment period was prescribed in 5 (50.0\%), 22 (34.4\%), and 1 (20.0\%) patients, respectively $(P=.48)$. 
TABLE 2 Primary and secondary outcomes per patient group

\begin{tabular}{|c|c|c|c|c|c|c|}
\hline & $\begin{array}{l}\text { Acute DVT } \\
\mathrm{N}=10\end{array}$ & $\begin{array}{l}\text { Chronic deep } \\
\text { venous obstruction } \\
\text { due to chronic } \\
\text { postthrombotic } \\
\text { sequelae, } N=64\end{array}$ & $P$ value $^{a}$ & $\begin{array}{l}\text { Chronic } \\
\text { deep venous } \\
\text { obstruction due to } \\
\text { (nonthrombotic) } \\
\text { iliac vein } \\
\text { compression } \\
\text { syndromes, } \mathrm{N}=5\end{array}$ & Total, $\mathrm{N}=79$ & $P$ value \\
\hline \multicolumn{7}{|l|}{ Type of intervention } \\
\hline PTA with stenting & $9(90.0)$ & 46 (71.9) & .42 & $5(100.0)$ & $60(75.9)$ & .20 \\
\hline PTA with stenting and AVF & $0(0.0)$ & $2(3.1)$ & .76 & $0(0.0)$ & $2(2.5)$ & .79 \\
\hline $\begin{array}{l}\text { Endophlebectomy with PTA and } \\
\text { stenting }\end{array}$ & $0(0.0)$ & $3(4.7)$ & .95 & $0(0.0)$ & $3(3.8)$ & .69 \\
\hline Left & $5(50.0)$ & $30(46.9)$ & 1.00 & $1(20.0)$ & $36(45.6)$ & .49 \\
\hline Right & $0(0.0)$ & $9(14.1)$ & 1.00 & $1(20.0)$ & $10(12.7)$ & .41 \\
\hline Caval & $0(0.0)$ & $3(4.7)$ & .95 & $1(20.0)$ & $4(5.1)$ & .24 \\
\hline Bilateral (incl. cava) & $4(40.0)$ & $10(15.6)$ & .17 & $0(0.0)$ & $14(17.7)$ & .10 \\
\hline Left incl. cava & $0(0.0)$ & $10(15.6)$ & 1.00 & $1(20.0)$ & 11 (13.9) & .38 \\
\hline Right incl. cava & $1(10.0)$ & $2(3.1)$ & .72 & $0(0.0)$ & $3(3.8)$ & .51 \\
\hline Azygos vein & $0(0.0)$ & $0(0.0)$ & .29 & $1(20.0)$ & $1(1.3)$ & .001 \\
\hline \multicolumn{7}{|l|}{ Type of anticoagulant ${ }^{c}$} \\
\hline Acenocoumarol & $9(90.0)$ & $33(51.6)$ & .04 & $3(60.0)$ & $45(57.0)$ & .07 \\
\hline $2.5-4.0$ & $4(40.0)$ & $34(53.1)$ & .67 & $1(20.0)$ & $39(49.4)$ & .30 \\
\hline INR, mean & $3.08( \pm 0.63)$ & $3.15( \pm 0.46)$ & .69 & $3.12( \pm 0.38)$ & $3.14( \pm 0.47)$ & .92 \\
\hline Time within therapeutic range, \% (mean) & $66.8( \pm 13.6)$ & $63.2( \pm 19.5)$ & .69 & $67.7( \pm 24.9)$ & $64.01( \pm 19.01)$ & .80 \\
\hline Proportion INR < 2.0, \% (mean) & $17.3( \pm 17.9)$ & $10.7( \pm 10.5)$ & .36 & $12.2( \pm 15.4)$ & $11.62( \pm 11.95)$ & .35 \\
\hline \multicolumn{7}{|c|}{ LMWH indicated if INR $<2.5$ beyond the initial treatment period ${ }^{d}$} \\
\hline Yes & $5(50.0)$ & $22(34.4)$ & .54 & $1(20.0)$ & $28(35.4)$ & .48 \\
\hline No & $5(50.0)$ & $42(65.6)$ & .54 & $4(80.0)$ & $51(64.6)$ & .48 \\
\hline Bleeding & $0(0.0)$ & $2(3.1)$ & .76 & $0(0.0)$ & $2(2.5)$ & .79 \\
\hline
\end{tabular}

Note: Results of the primary and secondary outcomes are in $\mathrm{n}(\%)$, mean ( $\pm \mathrm{SD}$ ), or median (interquartile range) as appropriate.

AVF, arteriovenous fistula; DVT, deep vein thrombosis; INR, International Normalized Ratio; LMWH, low-molecular-weight heparin; PTA, percutaneous transluminal angioplasty.

${ }^{a} P$ value based on comparison between patients with an acute DVT $(n=10)$ versus patients with chronic deep venous obstruction due to postthrombotic sequelae $(n=64)$.

${ }^{\mathrm{b}} P$ value based on comparison between patients with an acute DVT $(n=10)$ versus patients with chronic deep venous obstruction due to postthrombotic sequelae $(n=64)$ versus patients with chronic deep venous obstruction due to (nonthrombotic) iliac vein compression syndromes $(n=5)$.

${ }^{\mathrm{c}}$ Antiplatelet agents were not part of standard care. A combined or subsequent treatment with carbasalatecalcium, rivaroxaban, or fraxiparin was seen in 3, 7, and 1 patient, respectively.

${ }^{d}$ Anticoagulant therapy was preformed according to international guidelines ${ }^{5}$ in all patients. This included LMWH use if INR dropped below 2.0 during the initial VKA (re)installment period. The initial treatment period was defined as the first 6 wks of (re)installment of VKA treatment following the performed stent placement. In some patients, supplementary low-molecular-weight heparin use was prescribed temporarily in case the INR dropped below 2.5 beyond the initial treatment period. 
There was no recurrent venous thromboembolism $(P=.97)$, and major bleeding ( $n=2$ ) occurred only in patients treated for chronic postthrombotic morbidity $(P=.79)$. The major bleedings concerned a subdural hematoma and an intracapsular hepatic bleeding.

Using the ROC curves, a TTR cutoff point of $49.9 \%$ was found for an increased risk of developing in-stent thrombosis in the total study population. The Kaplan-Meier curve in Figure 1 shows a significantly lower cumulative incidence for in-stent thrombosis in patients with

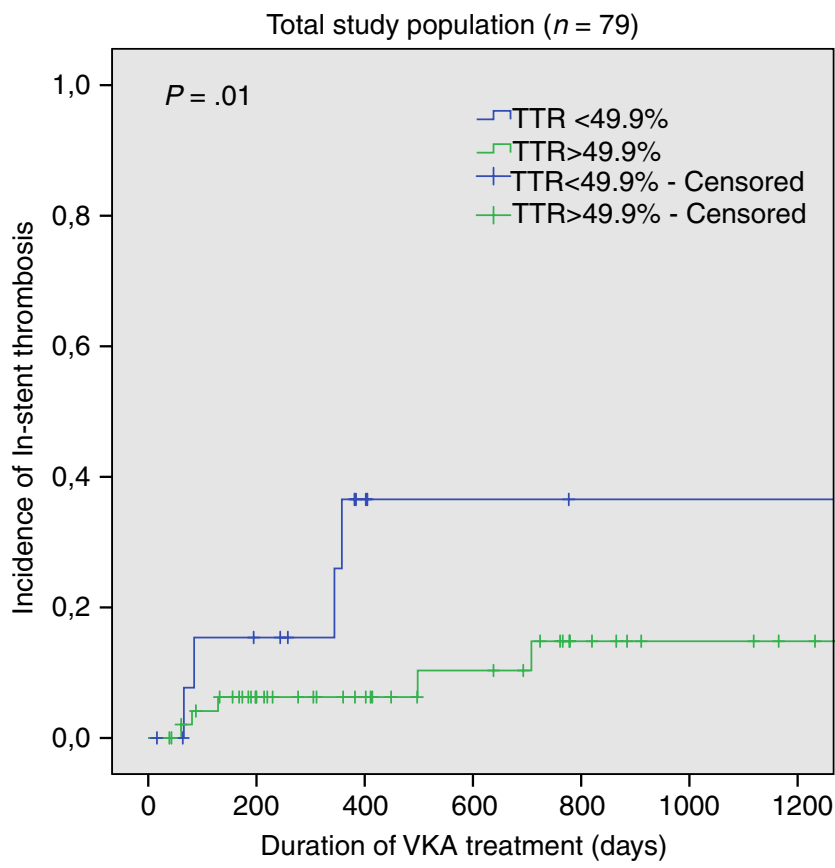

FIGURE 1 Kaplan-Meier: In-stent thrombosis comparing overall TTR $^{*}<$ or $>49.9 \%$. Kaplan-Meier curve presenting the development of in-stent thrombosis during VKA treatment comparing patients with an overall TTR $<$ or $>49.85 \%$. The cutoff was based on the optimal combination of values (highest "sensitivity" and "1-specificity") in the accompanying ROC curves. ${ }^{*}$ TTR is calculated using the method as proposed by Rosendaal et al. ${ }^{28} \mathrm{ROC}$, receiver operating characteristic; TTR, time within therapeutic range; VKA, vitamin $\mathrm{K}$ antagonist a TTR $\geq 49.9 \%$ compared to patients with a TTR $<49.9 \%(P=.01)$. Specified TTR cutoff points for patients treated in the acute phase or patients treated for chronic postthrombotic sequelae were $69.4 \%$ and $45.9 \%$, respectively. Furthermore, overall an increased risk of in-stent thrombosis was seen when the INR was $<2.0$ for more than $9.9 \%$ of the time. In patients treated for an acute DVT, an increased risk of in-stent thrombosis was seen with an INR $<2.0$ for more than $21.7 \%$ of the time and in the case of chronic deep venous obstruction with postthrombotic sequelae, the cutoff point was determined at $9.9 \%$. Lower TTR (TTR < 49.9\%) was associated with a higher proportion INR $<2.0(P=.03)$.

The Cox regression analyses according to the various models in patients stented for chronic deep venous obstruction with postthrombotic sequelae $(n=64)$ are presented in Table 3 . An increased risk of in-stent thrombosis associated with decreasing TTR was found in all models: the univariate model, the model adjusted for age and sex, the model adjusted for sex and VKA type, as well as the multivariable adjusted model. Per $1 \%$ TTR increase, this resulted in HR of $0.96(0.92-0.99 ; P=.02)$ for all models. Per $10 \%$ TTR increase, all models showed an HR of $0.65(0.46-0.94 ; P=.02)$. For the proportion INR $<2.0$ no significant impact on in-stent thrombosis development could be demonstrated.

Figure $2 \mathrm{~A}$ shows median TTRs between patients with and without in-stent thrombosis: 58.9\% (IQR, 38.4-73.7) versus 67.6\% (IQR, 56.4-76.3), respectively $(P=.15)$. For patients that had experienced an in-stent thrombosis TTR is further subdivided according to treatment indication and shown in Figure 2B: with a median TTR of $68.0 \%$ (IQR, 49.8-90.4) in patients treated during the acute phase versus 43.9\% (IQR, 35.6-71.6) in patients treated for chronic deep venous obstruction with postthrombotic sequelae $(P=.27)$.

\section{4 | DISCUSSION}

In this study, we found that the quality of anticoagulant therapy was an important independent determinant for the development of in-stent thrombosis in patients after cavo-iliofemoral venous stent placement.

TAB LE 3 Hazard ratios for IST after stenting for chronic postthrombotic deep venous obstruction $(n=64)$

\begin{tabular}{lllll} 
& Univariable & Age/Sex adjusted & Sex/VKA type adjusted & Multivariable adjusted $^{\mathrm{c}}$ \\
\hline TTR (per 1\% increase) & $0.96(0.92-0.99)^{\mathrm{d}}$ & $0.96(0.92-0.99)^{\mathrm{d}}$ & $0.96(0.92-0.99)^{\mathrm{d}}$ & $0.96(0.92-0.99)^{\mathrm{d}}$ \\
\hline TTR (per 10\% increase) & $0.65(0.46-0.94)^{\mathrm{d}}$ & $0.65(0.46-0.94)^{\mathrm{d}}$ & $0.65(0.46-0.94)^{\mathrm{d}}$ & $0.65(0.46-0.94)^{\mathrm{d}}$ \\
INR $<2.0$ (per 1\% increase) & $1.01(0.93-1.09)$ & $0.99(0.91-1.07)$ & $0.99(0.92-1.07)$ & $0.98(0.91-1.06)$ \\
$\begin{array}{l}\text { INR }<2.0 \text { (per 10\% } \\
\text { increase) }\end{array}$ & $1.09(0.48-2.46)$ & $0.86(0.37-2.00)$ & $0.89(0.41-1.95)$ & $0.83(0.37-1.86)$ \\
\end{tabular}

Note: Results are hazard ratio $(95 \% \mathrm{CI})$ for IST development after venous stent placement indicated for chronic deep venous obstruction due to postthrombotic sequelae $(n=64)$.

INR, International Normalized Ratio; IST, in-stent thrombosis; TTR, time within therapeutic range.

${ }^{\text {a }}$ Adjusted for age and sex.

${ }^{\mathrm{b}}$ Adjusted for sex and VKA type (acenocoumarol or phenprocoumon).

${ }^{\mathrm{c}}$ Adjusted for age, sex, VKA type (acenocoumarol or phenprocoumon), and indication for LMWH use if INR $<2.5$ following initial treatment period. ${ }^{\mathrm{d}} P=.02$ 
(A)

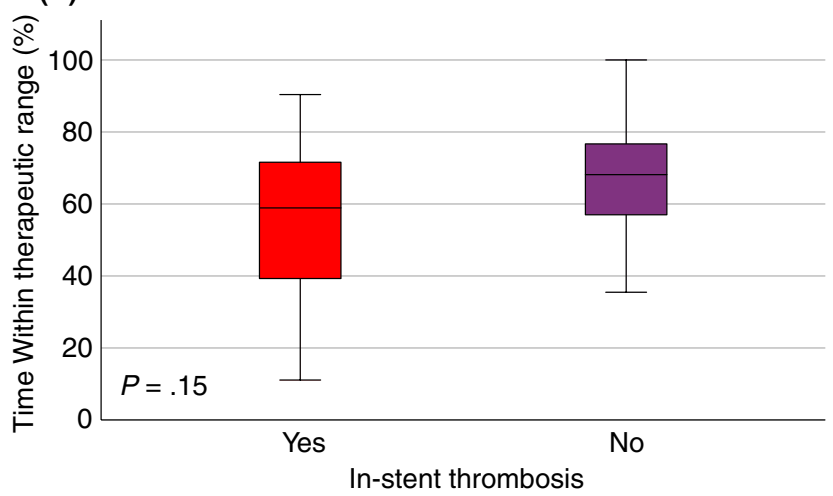

(B)

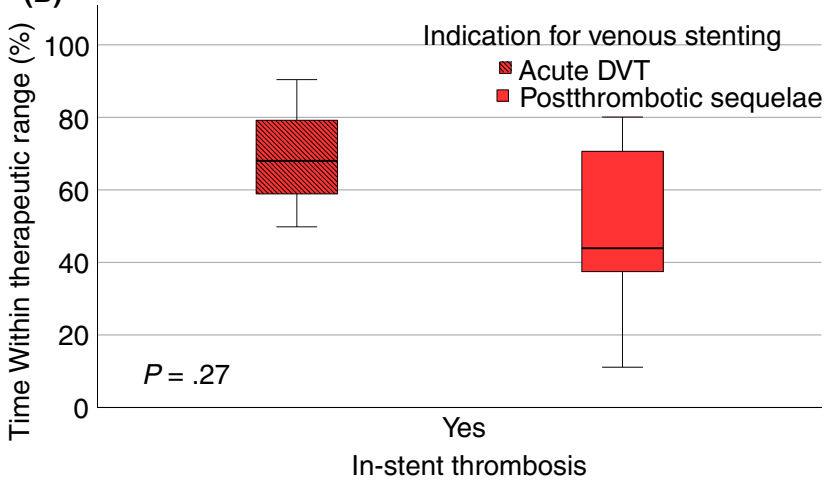

FIGURE 2 A, TTR* in patients with and without in-stent thrombosis. Box-plot presenting the absolute TTR for patients with IST versus patients who did not develop IST. The box line represents the median, the box edges the 25 th and 75 th percentile, and the whiskers indicate the maximum values minus outliers. $\mathrm{B}, \mathrm{TTR}^{*}$ in patients with in-stent thrombosis, categorized per treatment indication. Box plot presenting the absolute TTR for patients with IST, categorized per treatment indication: acute DVT or chronic deep venous obstruction due to postthrombotic sequelae. The box line represents the median, the box edges the 25th and 75th percentile, and the whiskers indicate the maximum values minus outliers. DVT, deep vein thrombosis; IST, in-stent thrombosis; TTR, time within therapeutic range. *TTR calculated as proposed by Rosendaal et al. ${ }^{28}$

We identified TTR as the most important predictive variable reflecting the quality of anticoagulant therapy and its associated risk for in-stent thrombosis. The impact of the quality of anticoagulant treatment was found to be significant, showing that a $1 \%$ lower TTR was associated with a $4.2 \%$ increased risk of in-stent thrombosis, and each $10 \%$ lower TTR was associated with a $34.6 \%$ increased risk of in-stent thrombosis.

We anticipated that for the onset of in-stent thrombosis, the proportion of INR values < 2.0 would be even more important. However, we could not demonstrate a difference in proportion of INR $<2.0$ between groups. This may be due to the relatively small sample size and the lack of contrast in the population. The use of thromboprophylaxis in case the INR would drop below $<2.5$ in patients who developed in-stent thrombosis and those who did not may have resulted in this lack of contrast and might explain why subtherapeutic INR could not be identified as a risk factor in this population.
The mean TTRs did not differ between patients with or without in-stent thrombosis; there was, however, a significantly higher number of in-stent thromboses over time in patients with TTR $<49.9 \%$. An explanation for this could be that patients with low TTR experience more periods of INR fluctuation with variable efficacy of VKA; during periods of decreasing effects of anticoagulant, the relatively low concentrations of the natural anticoagulants protein $\mathrm{C}$ and protein $\mathrm{S}$, compared to the quickly rising concentrations of active vitamin $\mathrm{K}$-dependent procoagulant factors VII, IX, and X and prothrombin, might induce a temporary prothrombotic state irrespective of the INR value and may contribute to the risk of stent occlusion.

The target ranges used for anticoagulant treatment were at the discretion of the treating physician. Although patients with a "high" target INR presented with more severe venous disease, groups were highly comparable regarding baseline and interventional characteristics. One might speculate that a worse clinical presentation may have prompted physicians to prescribe a higher target INR or that patients treated according to the "high" target INR had more serious postthrombotic morbidity based on a more pronounced thrombogenic risk profile. However, this could not be determined from our data. Either way, a "high" target INR did not provide better protection against in-stent thrombosis than the conventional "low" target INR.

At the time of this study, all patients received VKAs. No DOACs were prescribed, mainly because the uptake of DOACs in the Dutch medical practice has been relatively slow, and physicians might also have been hesitant to adopt DOACs and thereby change medication in patient groups presenting with more severe postthrombotic morbidity. Treatment with DOACs provides more stable anticoagulation and has been associated with improved recanalization and reduced incidence of postthrombotic syndrome. ${ }^{31,32}$ It is therefore possible that DOACs might provide better protection against in-stent thrombosis, although this has not yet been objectified and requires further clinical study. ${ }^{33}$

An important limitation is the small sample size of our study. This can be explained by the fact that venous stenting was and still is a relatively new treatment modality that is not yet performed on a large scale. However, although over time venous stenting is being performed more frequently and experience with these procedures has increased, the risk of developing in-stent thrombosis following venous stent placement remains high. ${ }^{9}$ Another limitation associated with the small sample size is the fact that it is impossible to assess the contribution of specific characteristics of the stents used (eg, type, material, length, diameter), or the interventions performed (eg, stented vein segments, used technique, achieved patency) to the development of in-stent thrombosis.

This study has several strengths including the prospective design, the clear definition of end points, objectively documented recurrence, and regular follow-up of patients.

We conclude that the quality of anticoagulant treatment reflected in the TTR following a venous stenting procedure is an important determinant for the risk of in-stent thrombosis. Moreover, a "high" target INR does not result in a reduced risk of in-stent 
thrombosis compared to the regular "low" target INR but might induce excess morbidity. The role of anticoagulant treatment including the use of DOACs for the prevention of in-stent thrombosis following stenting procedures merits further research.

\section{ACKNOWLEDGMENTS}

None

\section{RELATIONSHIP DISCLOSURE}

The authors declare nothing to report.

\section{AUTHOR CONTRIBUTIONS}

PN analyzed the data, drafted, and revised the paper. JHHvL, MAFdW, and RLMK collected data and critically reviewed the draft paper. PE provided a first draft of the database, did a preliminary analysis, and critically reviewed the draft paper. $\mathrm{HtC}$ participated in its design and coordination and critically reviewed the draft paper. AJtC-H conceived the study, supervised data collection, supervised the analysis, and revised the draft paper. All authors had full access to all of the study data (including statistical reports and tables) and take responsibility for the integrity of the data and the accuracy of the data analysis. All authors contributed to the interpretation of the data, approved the final draft of the paper, and take responsibility for the integrity of the work as a whole.

\section{ORCID}

Pascale Notten (iD https://orcid.org/0000-0002-8270-2000

\section{REFERENCES}

1. van Vuuren T, de Wolf MAF, Arnoldussen C, Kurstjens RLM, van Laanen JHH, Jalaie H, et al. Editor's Choice - Reconstruction of the femoro-ilio-caval outflow by percutaneous and hybrid interventions in symptomatic deep venous obstruction. Eur J Vasc Endovasc Surg. 2017;54(4):495-503.

2. Manninen H, Juutilainen A, Kaukanen E, Lehto S. Catheter-directed thrombolysis of proximal lower extremity deep vein thrombosis: a prospective trial with venographic and clinical follow-up. Eur J Radiol. 2012;81(6):1197-202.

3. Sharifi M, Mehdipour M, Bay C, Smith G, Sharifi J. Endovenous therapy for deep venous thrombosis: the TORPEDO trial. Catheter Cardiovasc Interv. 2010;76(3):316-25.

4. Baekgaard N, Broholm R, Just S, Jorgensen M, Jensen LP. Long-term results using catheter-directed thrombolysis in 103 lower limbs with acute iliofemoral venous thrombosis. Eur J Vasc Endovasc Surg. 2010;39(1):112-17.

5. Neglen P, Hollis KC, Olivier J, Raju S. Stenting of the venous outflow in chronic venous disease: long-term stent-related outcome, clinical, and hemodynamic result. J Vasc Surg. 2007;46(5):979-90.

6. Prandoni P, Lensing AW, Prins MH, Pesavento R, Piccioli A, Sartori $M T$, et al. The impact of residual thrombosis on the long-term outcome of patients with deep venous thrombosis treated with conventional anticoagulation. Semin Thromb Hemost. 2015;41(2):133-40.

7. Kahn SR, Shrier I, Julian JA, Ducruet T, Arsenault L, Miron MJ, et al. Determinants and time course of the postthrombotic syndrome after acute deep venous thrombosis. Ann Intern Med. 2008;149(10):698-707.
8. Schulman S, Lindmarker P, Holmstrom M, Larfars G, Carlsson A Nicol P, et al. Post-thrombotic syndrome, recurrence, and death 10 years after the first episode of venous thromboembolism treated with warfarin for 6 weeks or 6 months. J Thromb Haemost. 2006;4(4):734-42.

9. Notten P, ten Cate-Hoek AJ, Arnoldussen C, Strijkers RHW, de Smet A, Tick LW, et al. Ultrasound-accelerated catheter-directed thrombolysis versus anticoagulation for the prevention of post-thrombotic syndrome (CAVA): a single-blind, multicentre, randomised trial. Lancet Haematol. 2020;7(1):e40-49.

10. Vedantham S, Goldhaber SZ, Julian JA, Kahn SR, Jaff MR, Cohen DJ, et al. Pharmacomechanical catheter-directed thrombolysis for deep-vein thrombosis. N Engl J Med. 2017;377(23):2240-52.

11. Haig Y, Enden T, Grotta O, Klow NE, Slagsvold CE, Ghanima W, et al. Post-thrombotic syndrome after catheter-directed thrombolysis for deep vein thrombosis (CaVenT): 5-year follow-up results of an open-label, randomised controlled trial. Lancet Haematol. 2016;3(2):e64-71.

12. Enden T, Haig Y, Klow NE, Slagsvold CE, Sandvik L, Ghanima W, et al. Long-term outcome after additional catheter-directed thrombolysis versus standard treatment for acute iliofemoral deep vein thrombosis (the CaVenT study): a randomised controlled trial. Lancet. 2012;379(9810):31-8.

13. Kim JY, Choi D, Guk Ko Y, Park S, Jang Y, Lee DY. Percutaneous treatment of deep vein thrombosis in May-Thurner syndrome. Cardiovasc Intervent Radiol. 2006;29(4):571-75.

14. Milinis K, Thapar A, Shalhoub J, Davies AH. Antithrombotic therapy following venous stenting: international Delphi consensus. Eur J Vasc Endovasc Surg. 2018;55(4):537-44.

15. Eijgenraam $P$, ten $C$ ate $H$, ten Cate-Hoek AJ. Venous stenting after deep venous thrombosis and antithrombotic therapy: a systematic review. Rev Vasc Med. 2014;2:88-97.

16. Douketis JD, Spyropoulos AC, Spencer FA, Mayr M, Jaffer AK, Eckman $\mathrm{MH}$, et al. Perioperative management of antithrombotic therapy: Antithrombotic Therapy and Prevention of Thrombosis, 9th ed: American College of Chest Physicians Evidence-Based Clinical Practice Guidelines. Chest. 2012;141(2 Suppl):e326S-50S.

17. Mearns ES, Kohn CG, Song JS, Hawthorne J, Meng J, White CM, et al. Meta-analysis to assess the quality of international normalized ratio control and associated outcomes in venous thromboembolism patients. Thromb Res. 2014;134(2):310-19.

18. Palareti G, Legnani C, Cosmi B, Guazzaloca G, Cini M, Mattarozzi S. Poor anticoagulation quality in the first 3 months after unprovoked venous thromboembolism is a risk factor for long-term recurrence. J Thromb Haemost. 2005;3(5):955-61.

19. Chitsike RS, Rodger MA, Kovacs MJ, Betancourt MT, Wells PS, Anderson DR, et al. Risk of post-thrombotic syndrome after subtherapeutic warfarin anticoagulation for a first unprovoked deep vein thrombosis: results from the REVERSE study. J Thromb Haemost. 2012;10(10):2039-44.

20. van Dongen CJ, Prandoni P, Frulla M, Marchiori A, Prins MH, Hutten BA. Relation between quality of anticoagulant treatment and the development of the postthrombotic syndrome. J Thromb Haemost. 2005;3(5):939-42.

21. Arnoldussen C, Strijkers R, Lambregts D, Lahaye M, de Graaf R, Wittens C. Feasibility of identifying deep vein thrombosis characteristics with contrast enhanced MR-Venography. Phlebology. 2014;29(1 suppl):119-24.

22. Strijkers $\mathrm{RH}$, Arnoldussen $\mathrm{CW}$, Wittens $\mathrm{CH}$. Validation of the LET classification. Phlebology. 2015;30(1 Suppl):14-9.

23. de Graaf R, de Wolf M, Sailer AM, van Laanen J, Wittens C, Jalaie $\mathrm{H}$. Iliocaval confluence stenting for chronic venous obstructions. Cardiovasc Intervent Radiol. 2015;38(5):1198-204. 
24. Kearon C, Akl EA, Ornelas J, Blaivas A, Jimenez D, Bounameaux H, et al. Antithrombotic Therapy for VTE Disease: CHEST Guideline and Expert Panel Report. Chest. 2016;149(2):315-52.

25. Eklof B, Rutherford RB, Bergan JJ, Carpentier PH, Gloviczki P, Kistner $\mathrm{RL}$, et al. Revision of the CEAP classification for chronic venous disorders: consensus statement. J Vasc Surg. 2004;40(6):1248-52.

26. Rutherford RB, Padberg FT Jr, Comerota AJ, Kistner RL, Meissner $\mathrm{MH}$, Moneta GL. Venous severity scoring: An adjunct to venous outcome assessment. J Vasc Surg. 2000;31(6):1307-12.

27. Meissner $\mathrm{MH}$, Natiello $\mathrm{C}$, Nicholls SC. Performance characteristics of the venous clinical severity score. J Vasc Surg. 2002;36(5):889-95.

28. Rosendaal FR, Cannegieter SC, van der Meer FJ, Briet E. A method to determine the optimal intensity of oral anticoagulant therapy. Thromb Haemost. 1993;69(3):236-39.

29. Schulman S, Kearon C. Definition of major bleeding in clinical investigations of antihemostatic medicinal products in non-surgical patients. J Thromb Haemost. 2005;3(4):692-94.

30. Schulman S, Rhedin AS, Lindmarker P, Carlsson A, Larfars G, Nicol $P$, et al. A comparison of six weeks with six months of oral anticoagulant therapy after a first episode of venous thromboembolism. Duration of Anticoagulation Trial Study Group. N Engl J Med. 1995;332(25):1661-65.
31. Utne KK, Dahm A, Wik HS, Jelsness-Jorgensen LP, Sandset PM, Ghanima W. Rivaroxaban versus warfarin for the prevention of post-thrombotic syndrome. Thromb Res. 2018;163:6-11.

32. Prandoni P, Ageno W, Mumoli N, Zanatta N, Imberti D, Visona A, et al. Recanalization rate in patients with proximal vein thrombosis treated with the direct oral anticoagulants. Thromb Res. 2017;153:97-100.

33. Sebastian T, Hakki LO, Spirk D, Baumann FA, Periard D, Banyai M, et al. Rivaroxaban or vitamin-K antagonists following early endovascular thrombus removal and stent placement for acute iliofemoral deep vein thrombosis. Thromb Res. 2018;172:86-93.

How to cite this article: Notten P, van Laanen JHH, Eijgenraam

P, et al. Quality of anticoagulant therapy and the incidence of in-stent thrombosis after venous stenting. Res Pract Thromb

Haemost. 2020;4:594-603. https://doi.org/10.1002/ rth2.12330 